intervention may avert the requirement of expensive biological therapy as second-line treatment, which leads to improved overall cost-effectiveness. As a first step to address this issue, we performed a systematic literature review to appraise existing evidence relating to delay in diagnosis and cost-of-illness in DMARDnaïve newly-diagnosed RA patients.

Objectives: To identify whether disease duration before initiation of first DMARD therapy is a determinant of subsequent direct and indirect costs in DMARD-naïve RA patients.

Methods: We systematically searched Pubmed, EMBASE, CINAHL and Medline databases for published literature relating to rheumatoid arthritis, and direct and/ or indirect costs. We included studies with DMARD-naïve patients who fulfilled the

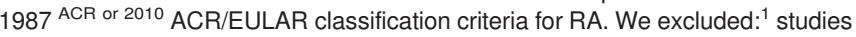
on non-rheumatoid arthritis patients, ${ }^{2}$ conference abstracts, systematic reviews or review articles; ${ }^{3}$ studies with no documented symptom duration prior to diagnosis ${ }^{4}$ studies which did not report direct and/or direct costs and/or health utilisation. All studies were required to report their methods and sources of respective cost measurements. We extracted the following data from each study; $;^{1}$ study design; ${ }^{2}$ potential determinants of RA cost; ${ }^{3}$ health economic outcomes and ${ }^{4}$ source of unit cost for the health-resources.

Results: A total of 173 records were identified in the systematic search, five of which included in the analysis. Two were cost-of-illness studies within the context of observational studies and the remaining were cost-of-illness studies alongside clinical trials. The health outcomes reported were heterogeneous: 1) Direct medical costs were reported in three studies; 2) Indirect non-medical costs were reported in one study and 3 ) Health-care utilisation was reported in one study. Only one study reported indirect costs from the societal perspective e.g. work disability. The definition of symptom duration was not specified in any studies. Three studies reported disease duration of one year or less and two studies reported symptom duration of six months and <two years. The timing and duration of the reported health economic outcomes varied widely (figure 1). The direct medical costs for three papers were adjusted for purchasing power parities and consumer price index for 2017 US Dollars.

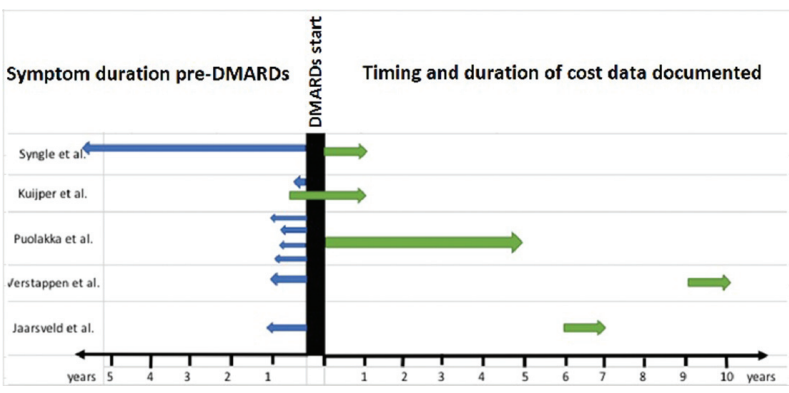

Abstract AB1233 - Figure 1

Conclusions: Data on the relationship between symptom duration and costs in DMARD-naïve RA patients is limited. Comparability between studies is hampered due to heterogeneity of the definition for symptom/disease duration and the health economic outcomes reported. An inception cohort of suspected/early RA should include data in resource utilisation and costs studies to identify the relationship between symptom duration and health economic outcomes.

Disclosure of Interest: None declared

DOI: 10.1136/annrheumdis-2018-eular.3967

\section{AB1234 WHAT HAPPENS IF IT ISN'T EARLY INFLAMMATORY ARTHRITIS? A RETROSPECTIVE CASE NOTE REVIEW OF PATIENTS REFERRED TO OUR EIA SERVICE WHO DID NOT HAVE EIA}

A.G. Pulikal ${ }^{1}$, T. Ahmed ${ }^{2}$, S. Levy ${ }^{2} .{ }^{1}$ Medical Student, St George's University of London; ${ }^{2}$ Rheumatology, Croydon University Hospital, London, UK

Background: Early inflammatory arthritis (EIA) has been a flagship subject for Rheumatology in the last few years. There has been a lot of interest in the patients diagnosed with EIA but less is known about those who enter the EIA pathway and are subsequently found not to have EIA.

Objectives: This study looks at the diagnoses and management of those dis charged from the EIA pathway and what impact this has on resources, management and time. Croydon University Hospital Rheumatology Department has been running an Early Inflammatory Arthritis service incorporating ultrasound since 2014. In this study we are looking at patients that were referred to the EIA Pathway from August 2014 to August 2015
Methods: To collect the data we looked at the patient records from our clinical system, Cerner Millennium. We recorded the clinical impression on first appointment, final diagnosis, additional investigations, referrals to therapies and other specialists and those that were discharged within the 6 weeks of referral. The data was analysed using. Microsoft Excel 2010

Results: Of the 368 patients who were referred to the EIA pathway 140 (38\%) were not diagnosed with EIA. The final diagnosis of these patients was osteoarthritis $29(26 \%)$, no rheumatological diagnosis $16(14 \%)$, soft tissue abnormality $11(9.8 \%)$, gout 7 (6.3\%), fibromyalgia/hypermobility 7 (6.3\%), SLE $5(4.5 \%)$ and polymyalgia rheumatica $4(3.6 \%)$. The remainder, $29(26 \%)$, had miscellaneous rheumatological diagnoses. Of the 140 patients, 28 were thought to have possible EIA on the first consultation. The final diagnosis in this group was osteoarthritis 7 (25\%), no rheumatological diagnosis 7 (25\%), soft tissue/musculoskeletal injury 3 (11\%) and fibromyalgia $2(7 \%)$. The remainder had miscellaneous diagnosis 9 $(32 \%)$. All patients had routine bloods and x-rays. In addition, musculoskeleta ultrasound was carried out in 22, MRI in 12, CT in 3 , EMG in 4 and 3 patients underwent bone density scanning. 13 were referred on to physiotherapy ( 8 were to hand therapy). 5 were referred to other medical specialities. 30 patients were discharged within 6 weeks.

Conclusions: This is the first study looking at those who did not have EIA. The Best Practice Tariff for EIA states that those without EIA should be discharged back to the GP within 6 weeks. We have shown that these patients have a variety of rheumatological diagnoses that require investigation, referral and treatment with the majority $(79 \%)$ remaining under our care at 6 weeks. This study highlights the resources needed to manage the patients attending rheumatology via the EIA pathway who do not have EIA and this should be taken into account when such a service is developed.

Disclosure of Interest: None declared

DOI: 10.1136/annrheumdis-2018-eular.1115

\section{AB1235 WORK PRODUCTIVITY AMONG WORKERS WITH AXIAL SPONDYLOARTHRITIS}

C.A. Lopes $^{1,2}$, F.M. Pimentel-Santos ${ }^{1,2}$, M. Mateus ${ }^{1}$, J.C. Branco ${ }^{1,2}$.

${ }^{1}$ Rheumatology, HOSPITAL EGAS MONIZ - CHLO; ${ }^{2}$ CEDOC, NOVA Medical

School, NOVA University of Lisbon, Lisbon, Portugal

Background: Axial Spondyloarthritis (axSpA) usually starts in early adulthood and the lifetime impact of the disease can be considerable. Pain, stiffness, sleep disturbances contribute to health-related quality of life reduction with significant impact in work productivity. Absenteeism and presenteeism are still responsible for high costs associated with the disease.

Objectives: Assess absenteeism, presenteeism, work and daily-activities impairment and their related associated factors in patients with axSpA.

Methods: Cross-sectional postal, unicenter, non-interventional study. Patients fulfilling the Assessment of Spa International Society Classification criteria for axSpA under working age were included. Two groups were defined: A) patients under current anti-TNF; B) patients under conventional therapy. Quantitative and qualitative surveys were performed: Work Productivity and Activity Impairment Questionnaire in SpA (WPAI); participants' experiences of working and their perceptions of how their condition had affected their work capacity and workplace relationships were recorded. The questionnaires were applied through a telephone call, after consent of the participant and respecting anonymity.

Results: 60 patients were included (table 1). No significant differences were found between the two groups. They worked on average $42 \pm 14.7$ hours per week $(\mathrm{h} / \mathrm{w})$ and missed $2.3 \pm 4.1 \mathrm{~h} / \mathrm{w}$ due to axSpA. Mean absenteeism, presenteeism, work and activities impairment due to axSpA were $6.8 \%, 32 \%, 35 \%$ and $41 \%$, respectively. The univariable analysis showed correlations between absenteeism and Visual Analogue Scale physician (phVAS) $(\mathrm{p}=0.027)$; presenteeism and Anquilosing Spondylitis disease activity score $-C$ reactive protein (ASDAS-CRP) $(p=0.002)$, Bath AS Disease Activity Index (BASDAI) $(p=0.03)$, Bath AS Functional Index (BASFI) $(p=0.02)$, VAS patient ( $p$ VAS) and phVAS $(p=0.01, p=0.006)$, erythrocyte sedimentation rate (ESR) $(p=0.03)$, CRP $(p=0.024)$; percent overall work impairment and ASDAS-CRP $(p=0.002)$, BASDAI $(p=0.019)$, BASFI $(\mathrm{p}=0.026)$, pVAS and phVAS $(\mathrm{p}=0.016, \mathrm{p}=0.01)$, ESR $(\mathrm{p}=0.03)$ and CRP $(p=0.03)$; percent activity impairment and BASDAI $(p=0.006)$, BASFI $(p=0.004)$, pVAS $(p=0.0004)$ and phVAS $(p=0.007)$. No correlation was found between work productivity and anti-TNF medication, education or marital status. Regression analysis revealed that BASDAI, BASFI, phVAS, pVAS and CRP accounted for $63 \%$ of the variance of presenteeism, with 10 points increase in phVAS resulted in an increase of $17 \%$ in presenteeism $(p=0.046)$. Over time, $95 \%$ had already gone to work sick: economic reasons $(60 \%)$, not liking staying at home even sick (43\%) and importance of work (35\%) were the major reasons to presenteeism. Overall, $63 \%$ considered that the disease can limit their projects or career progression; $56 \%$ had already cancelled or postponed work; $20 \%$ had already changed jobs and $15 \%$ stated that had already felt discriminated. 
Abstract AB1235 - Table 1. Patient demographics and clinical variables.

\begin{tabular}{|c|c|c|c|c|}
\hline & & $\begin{array}{c}\text { Group A } \\
\text { under current } \\
\text { biological therapy } \\
\text { (for at least } 6 \text { months } \\
n=31\end{array}$ & $\begin{array}{c}\text { Group B } \\
\text { conventional } \\
\text { therapy } \\
\mathrm{n}=29\end{array}$ & $\begin{array}{c}\mathrm{p}- \\
\text { valu } \\
\mathrm{e}\end{array}$ \\
\hline \multirow[t]{2}{*}{ Patients } & Male. female: $\mathrm{n}(\%)$ & $16(52 \%): 15(48 \%)$ & $21(72 \%): 8(28 \%)$ & 0.1 \\
\hline & Age: median (min-max) & $40(29-66)$ & $43(22-66)$ & 0.6 \\
\hline \multirow[t]{3}{*}{ Education } & Primary education (5-11 ages) & 8 & & 0.5 \\
\hline & Secondary education (11-18 ages) & 13 & 15 & \\
\hline & Tertiary education $(>18$ ages) & 10 & 10 & \\
\hline \multirow[t]{9}{*}{$\begin{array}{l}\text { Clinical } \\
\text { characteristics }\end{array}$} & $\begin{array}{l}\text { Number of anti-TNF; median (min- } \\
\text { max) }\end{array}$ & $1(1-4)$ & $\mathrm{NA}$ & \\
\hline & $\begin{array}{l}\text { Anti-TNF duration (months); mean } \\
\text { (min-max) }\end{array}$ & $30(6-63)$ & $\mathrm{NA}$ & \\
\hline & ASDAS CPR (mean. SD) & $1.59 \pm 0.97$ & $1.95 \pm 1.04$ & 0.1 \\
\hline & BASDAI (mean. SD) & $2.95 \pm 2.13$ & $2.41 \pm 2.11$ & 0.3 \\
\hline & BASFI (mean. SD) & $3.04 \pm 2.92$ & $1.82 \pm 2.43$ & 0.3 \\
\hline & VAS patient $(0-100)$ (mean. SD) & $31.04 \pm 24.53$ & $27.13=28.88$ & 0.4 \\
\hline & VAS physician $(0-100)$ (mean. SD) & $13.35 \pm 15.99$ & $15.98 \pm 16.81$ & 0.5 \\
\hline & ESR $(\mathrm{mm} / \mathrm{h})($ mean, SD) & $13.35 \pm 9.05$ & $14.21 \pm 11.11$ & 0.9 \\
\hline & CRP (mg/d) (mean. SD) & $0.56 \pm 0.56$ & $0.74=0.82$ & 0.4 \\
\hline \multirow{4}{*}{$\begin{array}{l}\text { Work } \\
\text { Productivity } \\
\text { and Activity } \\
\text { Impairment } \\
\text { Questionnaire } \\
\text { in Spa (WPAI) }\end{array}$} & $\begin{array}{l}\text { Absenteeism (Percent work time } \\
\text { missed due to problem) }(\%)\end{array}$ & $7.6 \%$ & $5.8 \%$ & 0.6 \\
\hline & $\begin{array}{l}\text { Presenteeism (Percent impairment } \\
\text { while working due to problem) }(\%)\end{array}$ & $30.9 \%$ & $34 \%$ & 0.7 \\
\hline & $\begin{array}{l}\text { Percent overall work impairment due to } \\
\text { problem }(\%)\end{array}$ & $34.2 \%$ & $35.9 \%$ & 0.9 \\
\hline & $\begin{array}{l}\text { Percent activity impairment due to } \\
\text { problem }(\%)\end{array}$ & $43.5 \%$ & $37.9 \%$ & 0.4 \\
\hline
\end{tabular}

Conclusions: Presenteeism, impairment of work productivity and activity were correlated with disease activity and physical functioning, with the increase of VAS physician resulting in increase in presenteeism. Economic reasons were the major factors to presenteeism and the majority of patients considered that the disease can limit their projects or career progression.

Disclosure of Interest: None declared

DOI: 10.1136/annrheumdis-2018-eular.4280

\section{AB1236 THERAPEUTIC ADHERENCE AND SATISFACTION IN A RHEUMATOLOGY CONSULTATION}

C. Iñiguez Ubiaga, C. Moriano, M. Garijo Bufort, A. Crespo Golmar, I. GonzalezFernandez, C. Alvarez Castro, A. Lopez Robles, M. Martin Martinez, E. Diez Alvarez, T. Perez Sandoval. Unidad de Reumatología, Complejo Hospitalario de León, León, Spain

Background: The lack of treatment adherence to is considered the main reason for therapeutic failure. It entails a high health care cost, both direct and indirect, affecting the patient's morbidity and mortality. In order to measure this adherence, there are different methods, which can be both objective and subjective. The ideal is the combination of both types in order to ensure that the data are as close as possible to reality.

Methods: We carried out an anonymous voluntary survey in October 2017 concerning the degree of satisfaction and therapeutic adherence of patients under follow-up in outpatient Rheumatology Consultations, selecting demographic data from them and using a MARS questionnaire for chronic diseases, which is validated in Spanish. This questionnaire consists of 30 questions that include items about beliefs, experiences and behaviour in terms of health. A score higher than 25 indicates good compliance, while a score lower means a suboptimal compliance.

Results: 201 surveys were collected, excluding those patients whose consultation was the first one and those who rejected their participation. The data analysis was performed descriptively with Microsoft Excel. $61 \%$ of the surveys collected were carried out by women, with an age range between 55 and 70 years (35\%). $45 \%$ of the patients surveyed had a basic level of education and $28 \%$ had an average level of education, representing both of them three quarters of our sample. When we analyse the treatments that our patients receive, the most prevalent are the DMARDs, which represent $35 \%$ of the treatments, followed by the corticotherapy and biological drugs (25\% and $16 \%$ respectively). Approximately $50 \%$ of the survey respondents stated that they had no problems with their medication, and in a small percentage (14\%), they claimed they had problems, mostly digestive in relation to the administration of subcutaneous Methotrexate. A $14.92 \%$ of questionnaires that were not correctly completed were discarded. Out of the 171 surveys, only one respondent was considered to have a good compliance, being the compliance of the remaining respondents suboptimal. This can be influenced by the limitations of understanding due to the language used, taking into account the characteristics of our population, mainly aged and with a primary level of education, as well as the place where the survey was completed. We obtained $74 \%$ of satisfaction with the information shared in the consultation, $73 \%$ considered that enough time was devoted to said consultation and $98 \%$ said they followed the treatment regimens. However, $11 \%$ and $21 \%$ said they changed the regimen according to their lifestyle and according to how the treatment made them feel and only $55 \%$ had clear treatment options available.

Conclusions: The lack of therapeutic adherence is one of the fundamental factors of therapeutic failure. There is no a single method for its assessment. Our patients show a suboptimal therapeutic compliance, although we have to take into account the limitations of the survey carried out. We must bear in mind the sociological aspects that can hinder adherence and re-assess it periodically for possible changes, as well as individualise each patient.

Disclosure of Interest: None declared

DOI: 10.1136/annrheumdis-2018-eular.7399

\section{AB1237 PATIENTS' PERSPECTIVES AND EXPERIENCE OF PSORIASIS AND PSORIATIC ARTHRITIS: A SYSTEMATIC REVIEW AND THEMATIC SYNTHESIS OF QUALITATIVE STUDIES}

D.J. Sumpton ${ }^{1,2,3}$, A. Kelly ${ }^{3,4,5}$, D.J. Tunnicliffe ${ }^{2,3}$, J.C. Craig $^{2,3}$, G. Hassett ${ }^{6}$, D. Chessman ${ }^{6}$, A. Tong ${ }^{2,3}$. 'Department of Rheumatology, Concord Repatriation General Hospital, Sydney; ${ }^{2}$ Sydney School of Public Health, The University of Sydney; ${ }^{3}$ Centre for Kidney Research, The Children's Hospital Westmead, Syndey; ${ }^{4}$ Department of Rheumatology, Canberra Hospital, Canberra; ${ }^{5}$ Department of Rheumatology, Liverpool Hospital, Sydney; ${ }^{6}$ Department of Rheumatology, Liverpool Hospital, Syndey, Australia

Background: Patients with psoriasis and psoriatic arthritis have a lower health related quality of life than the normal population and experience high rates of treatment dissatisfaction ${ }^{1}$. The complexity of unmet needs in diagnosis and treatment ${ }^{2}$ necessitate a deep understanding of the experience of people with both conditions to guide development of outcomes important to patients and improve patient centred care.

Objectives: To describe the perspectives and experiences of patients with psoriasis and psoriatic arthritis.

Methods: Databases (MEDLINE, Embase, PsycINFO, CINAHL) were searched to October 2016. Thematic synthesis was used to analyse the findings.

Results: From 46 studies ( $n=37$ psoriasis and $n=9$ psoriatic arthritis) involving 1290 adult patients with psoriasis $(n=1105)$ and psoriatic arthritis $(n=185)$ we identified six themes (with subthemes): suffering uncontrollable and ongoing upheaval (dictating life choices and course, disrupting role functioning, limited by debilitating symptoms, unstoppable and far reaching fatigue); weighed down by mental load (struggling with unrecognised distress, anxiety provoked by the volatility and constancy of symptoms, depleting motivation and pleasure); harbouring shame and judgement (marked as unhygienic and contagious, rejected and isolated, resenting own appearance, pain and embarrassment in intimacy); demoralised by inad equacies and burden of therapy (disappointed by unmet expectations of treatment benefit, daily drudgery, deterred by unpalatable or inconvenient treatments, disempowered by lack of personalised care, fearing long term side effects); gaining control (making sense of the condition, shutting the disease out, accepting a new health status, attuning to the body); and making confident treatment decisions (trading off perceptible benefits against safety and convenience relying on family input, reassured by clinician acknowledgement of fears, seeking empowering relationships with clinicians).

Conclusions: Patients with psoriasis and psoriatic arthritis contend with profound disruption in their functioning, roles and life course; fear deterioration of their health; and have unmet expectations about their treatment and care. Patients with psoriasis feel marked by their disease, stigmatised and rejected by others while patients with psoriatic arthritis experience social withdrawal and depleted motivation due to fatigue, joint impairment and pain. Establishing therapeutic relationships, addressing treatment expectations, and supporting psychosocial needs may help to improve satisfaction and outcomes in patients with psoriasis and psoriatic arthritis.

\section{REFERENCES:}

[1] Katherine M. Mercy, Kenneth B. Gordon, Amy S. Paller. Patient Satisfaction and Quality of Life in Psoriasis and Psoriatic Arthritis. JAMA. 2014;312 (24):2676-2677

[2] Helliwell, et al. Qualifying Unmet Needs and Improving Standards of Care in Psoriatic Arthritis. Arthritis Care \& Research Vol. 66, No. 12, December 2014, pp 1759-1766

Disclosure of Interest: None declared

DOI: 10.1136/annrheumdis-2018-eular.5161

\section{AB1238 THE SELF-MANAGEMENT MODEL IN THE AGENDA OF SUCCESSIVE CONSULTATIONS IN RHEUMATOLOGY}

D. Castro Corredor. Rheumatology service, Hospital General Universitario De Ciudad Real, Ciudad Real, Spain

Background: The rheumatology service of Ciudad Real Hospital, located in an autonomous community of that same name that is nearly in the centre of Spain, implemented a self-management model of successive appointments more than 